\title{
Mixing Phenomenon and Flow Field in Ladle of RH Process
}

\author{
Kaitian Zhang ${ }^{1,2}$, Heng Cui ${ }^{1, *}$, Rudong Wang ${ }^{1}$ and Yang Liu ${ }^{2}$ \\ 1 Collaborative Innovation Center of Steel Technology, University of Science and Technology Beijing, \\ Beijing 100083, China \\ 2 Engineering Research Institute, University of Science and Technology Beijing, No.30 Xueyuan Road, \\ Haidian District, Beijing 100083, China \\ * Correspondence: cuiheng@ustb.edu.cn; Tel.: +86-136-7123-9796
}

Received: 14 July 2019; Accepted: 13 August 2019; Published: 14 August 2019

check for updates

\begin{abstract}
Particle image velocimetry (PIV) system was adopted to investigate the relationship between the mixing phenomenon and the flow field of a $210 \mathrm{t} \mathrm{RH}$ degasser by a 1:4 scale water model. The results of mixing simulation experiments indicated that the mixing time decreased with the increase of gas blowing rate. However, with the increase of Snorkel immersion depth (SID), the mixing time presented a decreasing rend firstly and then increased. The measurement of flow fields of RH ladle by PIV system can explain the phenomenon above. According to the characteristics of the flow field in RH ladle, the flow field can be divided into the mixing layer, the transition layer, and the inactive layer. On the one hand, the stirring power in RH ladle and vacuum chamber both increases with more gas blowing rate, leading to the decrease of mixing time. On the other hand, with SID increases from $400 \mathrm{~mm}$ to $480 \mathrm{~mm}$, the gas blowing depth increase results in the mixing power increases, and the mixing time decreases at the beginning. Because of too much-molten steel in the vacuum chamber and the expanding of the inactive layer in RH ladle, however, the utilization rate of the gas driving force begins to decrease. Therefore, the mixing time started to increases with the increase of SID.
\end{abstract}

Keywords: RH degasser; physical simulation; mixing time; PIV; flow field

\section{Introduction}

As the the world economy develops and evolves, the pursuits of the steel products quality are gradually increasing, leading to the improvement requirements on the refining. Besides, the development of continuous casting also requires the matching of high refining efficiency. It has been proven [1-5] that Ruhrstahl-Heraeus (RH) vacuum refining, an important technology to improve product quality, reduce cost, and expand variety, has become the most widely used refining equipment in the world.

Mixing time is an important index to measure the refining efficiency of $\mathrm{RH}$, and it reflects the effect of mixing of the molten steel in the RH degasser [6-10]. To understand and master the relationship between the mixing time and the process parameters is significant to the design and optimization of the $\mathrm{RH}$ equipment and refining process.

The chemical compositions of samples taken from different positions in the RH ladle are different. This phenomenon illustrates that the molten steel in the RH ladle is not in a thoroughly mixed state [9]. The compositions of products are quickly out of the range when the steel grades are of narrow composition range. The mixing time can reflect the macrostate of molten steel mixed in the ladle, but it cannot explain the actual situation of molten steel flow, such as the presence or absence of inactive zones in the ladle and where they are, etc. [11,12]. The flow behavior of molten steel plays a decisive 
role in the refining effect of $\mathrm{RH}$ [13]. Therefore, it is needed to study the velocity distribution of $\mathrm{RH}$ ladle flow field further. However, RH vacuum refining is not a transparent process with complex reaction and transmission. The most direct and effective research method for RH ladle flow field is the simulation. Through simulation research, rules can be found out from the complicated process to serve the actual production process. There are many studies on $\mathrm{RH}$ vacuum refining process by physical [14-16] and numerical [17-20] model. For example, Li et al. [14] studied RH flow and mixing phenomenon and found that mixing time was usually 3 to 4 times of circulation time, and mixing time depends on its positions. The influence of snorkels shape and number on RH mixing time was studied by Ling et al. [15], and the relationship between optimal mixing conditions and numbers of snorkels was obtained. Moreover, He et al. [17] studied the mixing behavior and slag layer behavior under RH bottom blowing process by numerical simulation.

With the development of measurement technology, many advanced devices are used in research to make physical simulations quantifiable. Particle image velocimetry (PIV) is a transient, multi-point, and non-contact method for measuring the velocity of the flow field. It can record the velocity distribution of a large number of spatial points in a moment and provide abundant information on space structure and flow characteristics of the flow field. In this work, a 1:4 scale water RH model was established to simulate the process of refining. The velocity distribution of the flow field in the model was obtained by PIV system to explore the relationship between the flow field structure and the mixing phenomenon.

\section{Experiments}

\subsection{Similarity Principle}

According to similarity theory, the geometric dimension of the model and original RH must be kept similar. Moreover, the flow of molten steel in RH degasser is ruled by gravity, viscosity, and inertia, therefore the dimensionless numbers, Reynolds (Re) and fixed Froude (Fr), also should be kept equal.

\subsubsection{Geometric Similarity}

To understand the characteristic of mixing in the $210 \mathrm{t}$ RH degasser, a 1:4 scale water model was established. Table 1 gives the main parameters of industrial and model RH.

Table 1. Characteristic parameters of industrial and model RH.

\begin{tabular}{ccccccccc}
\hline \multirow{2}{*}{$\begin{array}{c}\text { Main } \\
\text { Parameters }\end{array}$} & \multicolumn{4}{c}{ Ladle/mm } & \multicolumn{3}{c}{$\begin{array}{c}\text { Vacuum } \\
\text { Chamber/mm }\end{array}$} & \multicolumn{3}{c}{ Snorkels/mm } \\
\cline { 2 - 9 } & $\begin{array}{c}\text { Upper } \\
\text { Internal } \\
\text { Diameter }\end{array}$ & $\begin{array}{c}\text { Lower } \\
\text { Internal } \\
\text { Diameter }\end{array}$ & Height & $\begin{array}{c}\text { Liquid } \\
\text { Level }\end{array}$ & $\begin{array}{c}\text { Internal } \\
\text { Diameter }\end{array}$ & $\begin{array}{c}\text { External } \\
\text { Diameter }\end{array}$ & $\begin{array}{c}\text { Internal } \\
\text { Diameter }\end{array}$ & Length \\
\hline $\begin{array}{c}\text { Prototype } \\
\text { Model }\end{array}$ & 3884 & 3222 & 4060 & 3300 & 2138 & 1294 & 650 & 1075 \\
\hline
\end{tabular}

\subsubsection{Dynamic Similarity}

Because of the Re of model and prototype RH in the second self-modeling region, so the disorder degree and the velocity distribution of fluid no longer change. Therefore, the researchers only need to keep the modified $F r$ of model and prototype equal in this study [10]. The relationship between model and the actual gas flow rate is shown as follows, which is derived from the modified $\mathrm{Fr}$ showing as following:

$$
Q_{m}^{o}=Q_{p}^{o} \sqrt{\left(\frac{1}{\lambda}\right)^{5} \frac{\rho_{w}}{\rho_{s}} \frac{\rho_{A r}^{o}}{\rho_{a}^{o}} \frac{P_{m}}{P_{p}} \frac{T_{p}}{T_{m}}}=K Q_{p}^{o}
$$

where, $\lambda$ are similarity scale, $Q_{m}^{o}$ and $Q_{p}^{o}$ are the flow rate of the air for model and Argon for prototype in the standard state, respectively, $\mathrm{L} \cdot \mathrm{min}^{-1} ; \rho_{w}, \rho_{s}, \rho_{A r^{\prime}}^{o}$ and $\rho_{a}^{o}$ are the density of water, molten steel, 
standard Argon, and standard air respectively, $\mathrm{kg} \cdot \mathrm{m}^{-3} ; P_{m}$ and $P_{p}$ is pressure of the air for model and Argon for prototype at outlet, respectively, $\mathrm{Pa} ; T_{m}$ and $T_{p}$ is temperature of the air for model and Argon for prototype at outlet, respectively, $K$. As the pressure at the air outlet changes with the immersion depth, different immersion depths correspond to different gas conversion coefficient $K$, and it is obtained by substituting relevant parameters into the above equation showing in Table 2 . Furthermore, all results by simulation experiments in this work were converted to prototype data by similarity coefficient for display.

Table 2. The conversion of gas flow rate between prototype and mold with different Snorkel immersion depths (SIDs).

\begin{tabular}{ccccccc}
\hline \multicolumn{2}{c}{ SID $(\mathbf{m m})$} & \multicolumn{2}{c}{ Outlet Pressure (Pa) } & \multicolumn{2}{c}{ Gas Flow Rate (L/min) } & \multirow{2}{*}{ K } \\
\cline { 1 - 5 } Prototype & Model & Prototype & Model & Prototype & Model & \\
\cline { 1 - 5 } 400 & 100 & 92,407 & $101,006.5$ & 1000 & 36.67 & 0.03667 \\
480 & 120 & 97,895 & $101,202.5$ & 1200 & 42.79 & 0.03566 \\
560 & 140 & 103,383 & $101,398.5$ & 1600 & 55.57 & 0.03473 \\
640 & 160 & 108,871 & $101,594.5$ & 2000 & 67.76 & 0.03388 \\
720 & 180 & 114,359 & $101,790.5$ & 2400 & 79.42 & 0.03309 \\
\hline
\end{tabular}

\subsection{Experimental Apparatus and Method}

\subsubsection{Experiment of Mixing}

The experimental devices of mixing are showing in Figure 1. A cube tank cover placed on the outside of the RH model. During the experiment, water fills up between the tank and RH model to prevent refraction of light, which affects PIV observation, from the cylinder wall of the RH model. A vacuum pump is used to keep the low air pressure in the vacuum chamber. Besides, Argon is blown out at the up-leg from a gas supply system to adjust the influence of gas flow rate on the flow field in RH. The mixing time transformed from electrical conductivity measured by a computer.

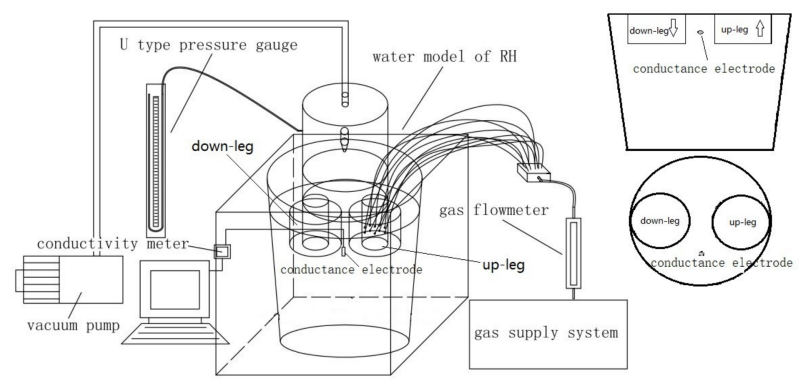

Figure 1. Schematic of the experimental apparatus.

When the devices stably, $200 \mathrm{~mL}$ of saturated sodium chloride solution was poured instantaneously into the vacuum chamber as a tracer. Then the conductivity instrument was applied to measure the changes in water solution conductivity. It is the mixing time when the conductivity change does not exceed the stable value plus or minus $5 \%$. The sampling time was $120 \mathrm{~s}$, and the sampling frequency was $25 \mathrm{~Hz}$. Each test repeated three times, and the average mixing time was the final result of the experiment, to obtain accurate results. Moreover, the position of the conductance electrode usually is the sampling location in the actual production process. Therefore, this position selected as the measurement point. 


\subsubsection{PIV System}

The experimental devices of PIV are showing in Figure 2. Amount of tiny hollow glass particles of 50 microns in diameter poured into the ladle as tracer particles. The tiny particles can follow the fluid and reflect the velocity of flow in the RH model. Then the dual-cavity laser shined on the ladle and, meanwhile, the CCD cameras take 100 photos in $50 \mathrm{~s}$ continuously. The PIV image data processing system calculated the average velocity of the 100 photos the, and it is the flow velocity distribution of the fluid in the ladle. Besides, the double frame mode was adopted to record the flow field from two angles, thus forming a cross record angle and achieving better accuracy.

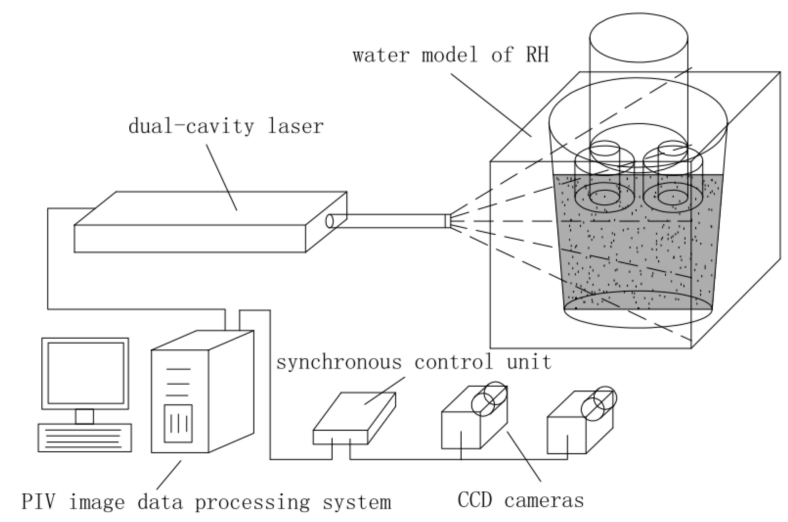

Figure 2. Particle image velocimetry (PIV) velocity measurement system of RH.

\section{Results}

\subsection{Effect of Gas Flow Rate and Snorkel Immersion Depth on Mixing Time}

Figure 3 shows the variation of mixing time against gas flow rate at five different SIDs. When the SID is $400 \mathrm{~mm}$, the mixing time significantly decreases with the increase of gas flow rate. Moreover, the decrease in mixing time becomes smaller and smaller. For the case of $480 \mathrm{~mm}$ and $560 \mathrm{~mm}$ SID, the mixing time decreases fast when the gas flow rate is less than $1200 \mathrm{~L} / \mathrm{min}$; meanwhile, the mixing time decreases slowly when the gas flow rate is higher than $1200 \mathrm{~L} / \mathrm{min}$. For the case of $640 \mathrm{~mm}$ and $720 \mathrm{~mm}$ SID, the mixing time decreases slowly with the increase of gas flow rate. Under different gas flow rates, the mixing time decreases first and then increases with the increase of SID. The mixing time of each gas flow rate in the $720 \mathrm{~mm}$ SID is the maximum and that for the case of $480 \mathrm{~mm}$ SID is the minimum.

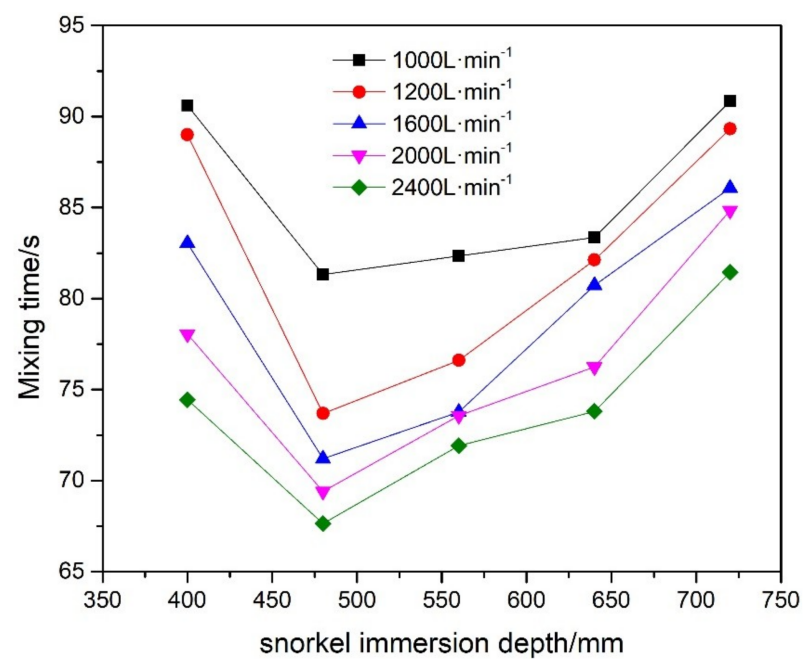

Figure 3. The effect of gas flow rate and SID on mixing time. 


\subsection{Characteristics of $R H$ Ladle Flow Field}

In this work, the flow field of RH ladle with different SIDs and gas flow rate were carried out by the PIV system. Take the $560 \mathrm{~mm}$ SID and the gas flow rate of $1600 \mathrm{~L} / \mathrm{min}$ as an example for analysis. Figure 4 is the result of the PIV system of different sections of the RH ladle flow field.
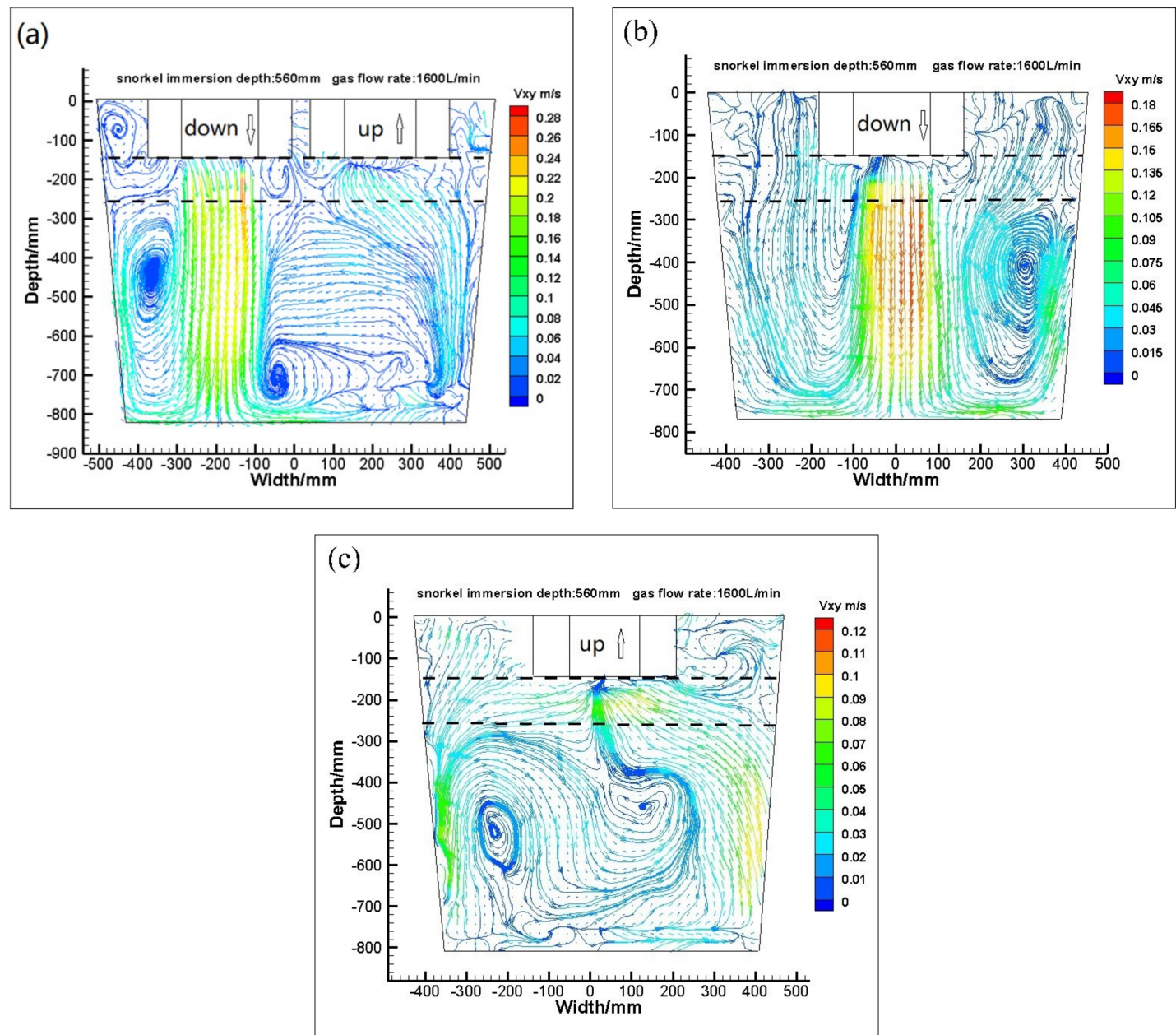

Figure 4. RH flow field by PIV system: (a) section of up-leg and down-leg; (b) section of down-leg; (c) section of up-leg.

The flow field of the section of up-leg and down-leg is showing in Figure 4a. In this section, the flow pattern mainly composed of the circulation flow from the down-leg to the up-leg and the return flow between the downward flow and the ladle wall. The velocity of the circulation flow and return flow is greater than $0.05 \mathrm{~m} / \mathrm{s}$. Among them, the velocity of downward flow is greater than $0.1 \mathrm{~m} / \mathrm{s}$ and the maximum velocity located at the outlet of the down-leg for $0.26 \mathrm{~m} / \mathrm{s}$. There are two other return flows, which are located between the downward flow and the upward flow and between the down-leg and the wall. The velocity of the two return flows is less than $0.05 \mathrm{~m} / \mathrm{s}$. The flow velocity of the areas between the two snorkels and between the snorkel and the wall of the ladle is less than 0.01 $\mathrm{m} / \mathrm{s}$, which identified as the inactive regions.

Figure $4 \mathrm{~b}$ shows the flow field of the section of the down-leg. The molten steel forms return flows between the downward flow and the wall. Besides, the velocity of downward flow is greater than $0.09 \mathrm{~m} / \mathrm{s}$, and the velocity of return flows between $0.01 \mathrm{~m} / \mathrm{s}$, and $0.09 \mathrm{~m} / \mathrm{s}$. The areas between the downward flow and the wall are the inactive regions, and their velocity is less than $0.01 \mathrm{~m} / \mathrm{s}$.

Figure $4 \mathrm{c}$ is the flow field of the section of the up-leg. The molten steel climb along the wall. Among them, a part of the flow into the up-leg and the velocity is greater than $0.03 \mathrm{~m} / \mathrm{s}$; the other part 
flows down and forms a return flow with the velocity of between $0.01 \sim 0.03 \mathrm{~m} / \mathrm{s}$. Furthermore, the velocity of the right-side return flow is slightly larger than the left side.

Synthesizing the three flow fields mentioned above, it can be found that the flow of molten steel in RH ladle is mainly the circulation flow from the down-leg to the up-leg and the return flow around the downward flow. The inactive region is mainly within the range of snorkel immersion depth. According to the characteristics of the flow field in RH ladle, the flow field can be divided into three different layers, as shown by the dotted line in Figure 4. From the bottom of the ladle to the upper boundary of the recirculation zone is the mixing layer. This layer is the main area of the mixing of the molten steel in the ladle because the circulation flow from the down-leg to the up-leg and the return flow around the downward flow greatly promote the mixing effect. Above the mixing layer and below the snorkel bottom is the transition layer for the exchange of molten steel between the vacuum chamber and the ladle in this layer, while the flow of the molten steel flowing out (in) the snorkel is almost no material and energy exchange because the flow is fast and consistent. The inactive layer is from the snorkel bottom to the surface of molten steel with a low velocity of disorderly flow. Because the snorkels divided this layer into many scattered small areas, the exchange of material and energy within the layer is blocked.

\subsection{RH Ladle Flow Field under Different Gas Flow Rate}

Figure 5 is the flow field of RH ladle at $560 \mathrm{~mm}$ SID and different gas flow rates by the PIV system. With the increase of gas flow rate, the structure of $\mathrm{RH}$ ladle flow field is consistent, and the maximum velocity of the downward flow is $0.248 \mathrm{~m} / \mathrm{s}, 0.251 \mathrm{~m} / \mathrm{s}, 0.254 \mathrm{~m} / \mathrm{s}$, and $0.257 \mathrm{~m} / \mathrm{s}$, respectively.

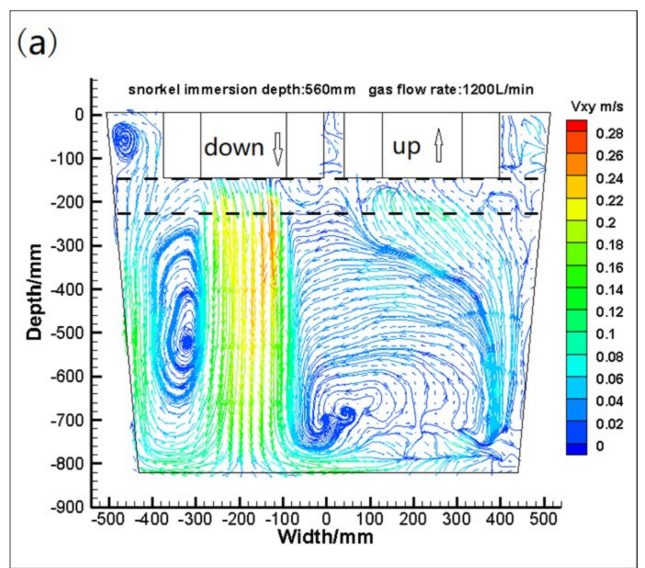

(c)

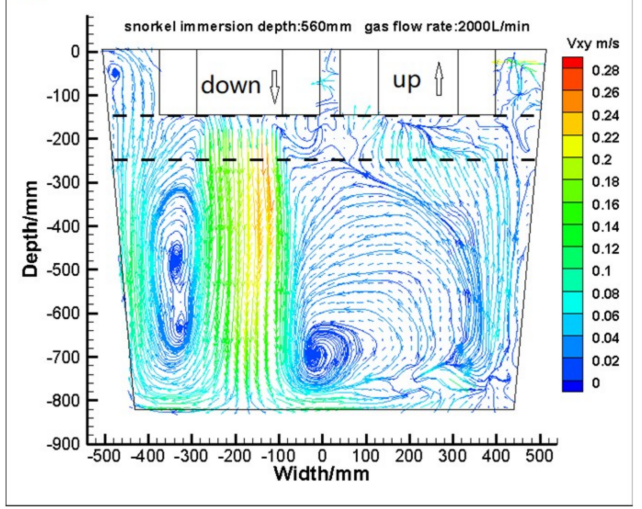

(b)
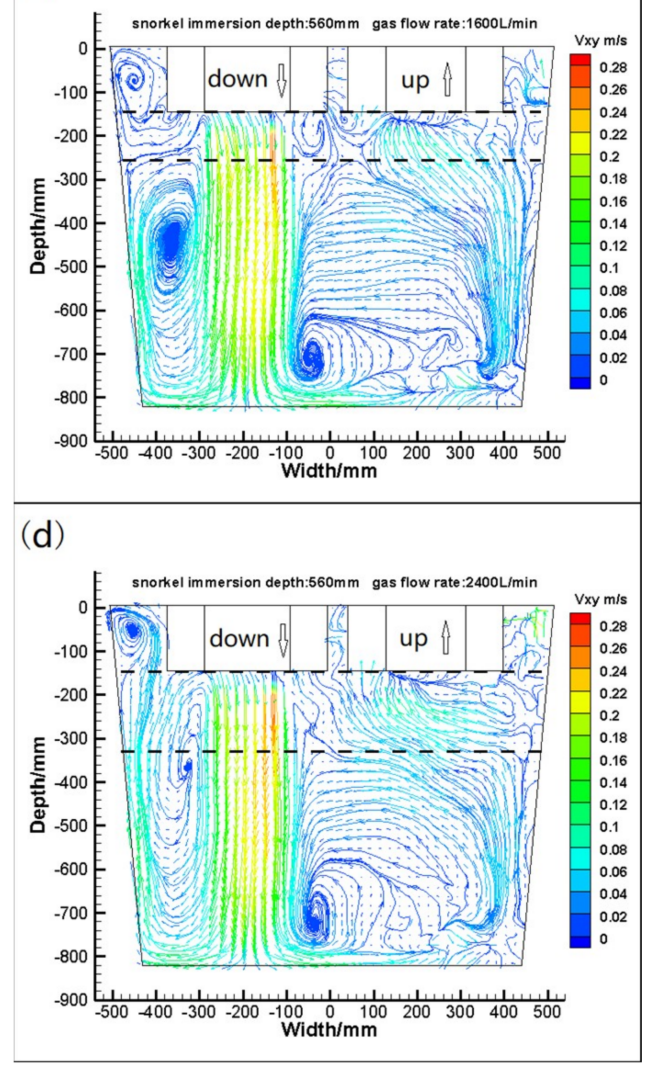

Figure 5. RH ladle flow field under different gas flow rates by PIV system: (a) $1200 \mathrm{~L} / \mathrm{min}$; (b) 1600 L/min; (c) $2000 \mathrm{~L} / \mathrm{min}$; (d) $2400 \mathrm{~L} / \mathrm{min}$. 
Figure 6 is the average of vertical velocity in the transition layer with different gas flow rate conditions. The vertical velocity on the left side of the downward flow is higher than zero, which means the molten steel flows upwards. The velocity of the downward flow is less than zero, which means the molten steel flows downward. Besides, the flow velocities with different gas flow rates are relatively consistent on the edge of the downward, but there is a separation phenomenon in the middle part. Maximum velocity of each operating condition does not locate in the center of the downward flow but the center-right. The vertical velocity in the middle of two snorkels is less than zero. Due to the pumping action of the up-leg to the molten steel, the flow is faster near the up-leg. Below the up-leg, the velocity curves in each operating condition relatively scatter, which indicates that the primary distinction of the molten steel flow on the transition layer results from the pumping action of the up-leg.

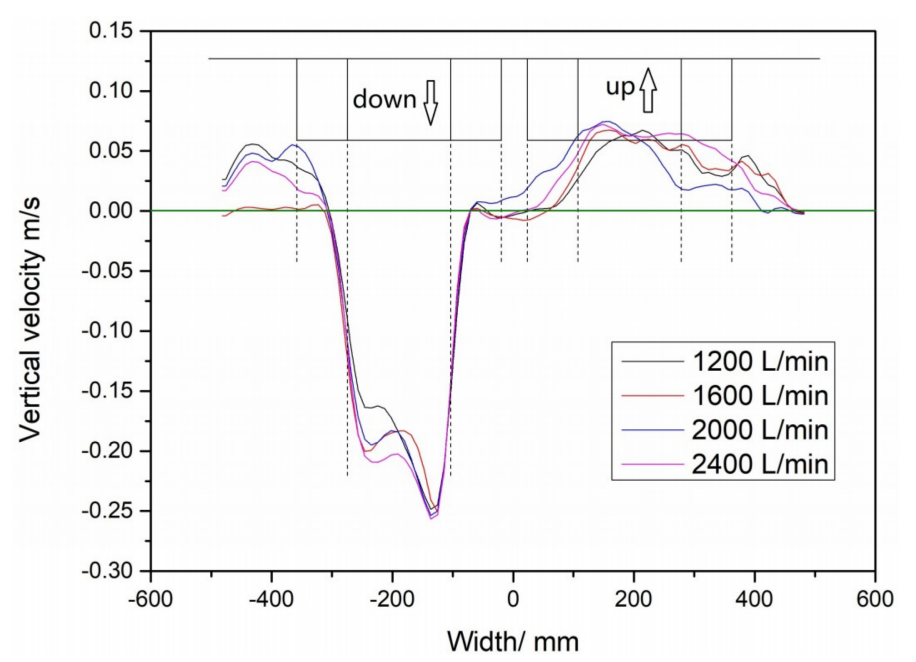

Figure 6. Vertical velocity distribution of flow field in transition layer under different gas flow rates.

Figure 7 is the average of vertical velocity in the mixing layer with different gas flow rates. With different gas flow rates, the velocity curves of the downward flow more comparatively disperse than that of in the transition layer. Besides, the maximum flow velocity of the mixing layer is less than the transition layer, and the maximum velocity is on the center of the downward flow. These phenomena above indicate that there is an oscillation in the process of the downward flow.

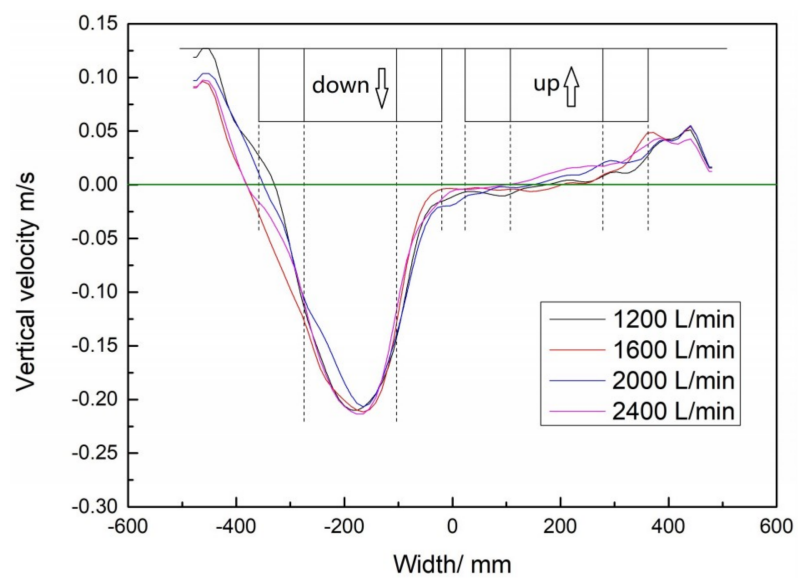

Figure 7. Vertical velocity distribution of flow field in mixing layer under different gas flow rates. 


\subsection{RH Ladle Flow Field under Different SIDs}

Figure 8 shows the flow fields of the RH ladle with the gas flow rate of $1600 \mathrm{~L} / \mathrm{min}$ and the SID changing from 400 to $720 \mathrm{~mm}$. With the increase of the SID, the patterns of RH ladle flow field are almost consistent, and the maximum velocity of the downward flow are $0.22 \mathrm{~m} / \mathrm{s}, 0.239 \mathrm{~m} / \mathrm{s}, 0.251 \mathrm{~m} / \mathrm{s}$, $0.273 \mathrm{~m} / \mathrm{s}$ and $0.294 \mathrm{~m} / \mathrm{s}$ respectively. Besides, the inactive layer and the transition layer become thicker with the increase of SID.
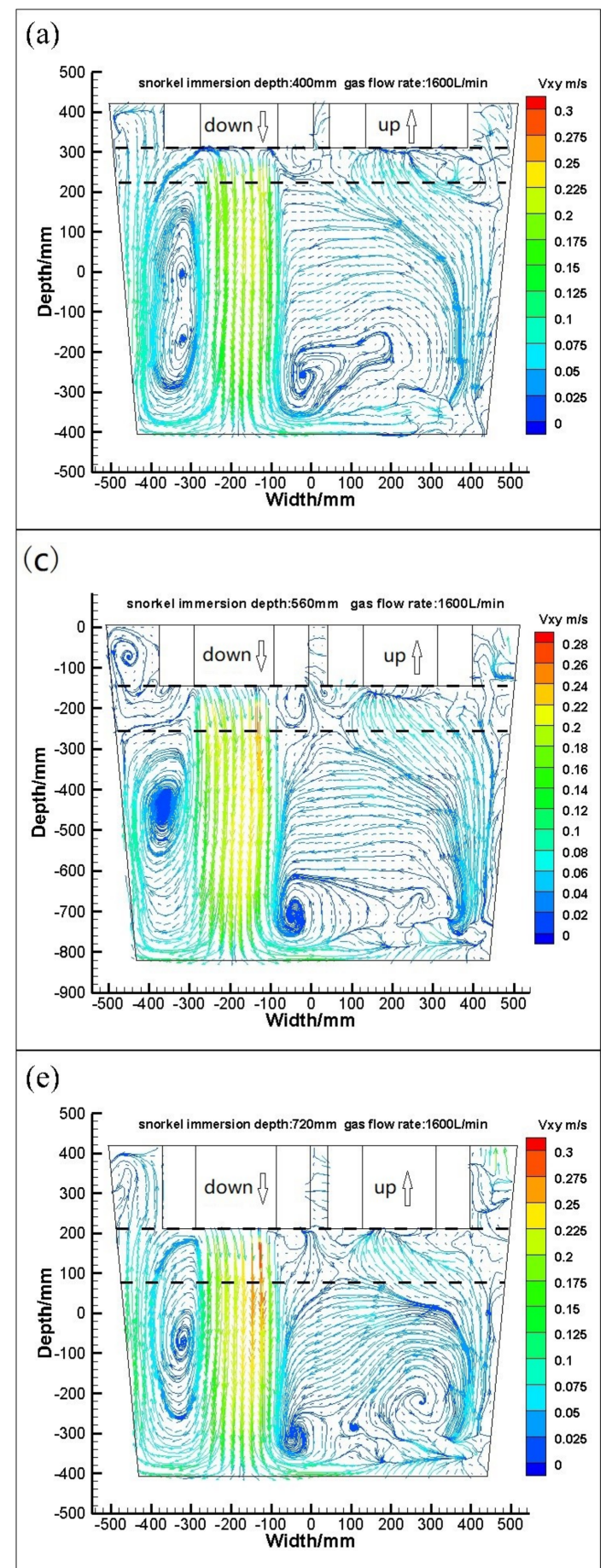

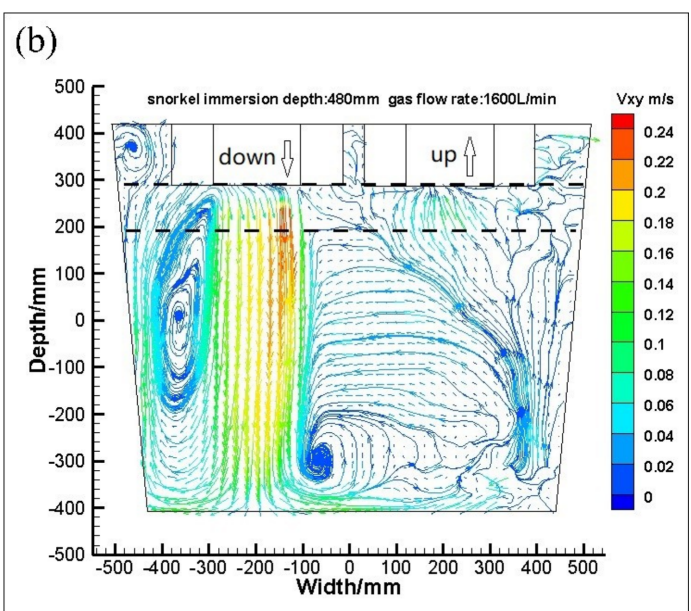

(d)

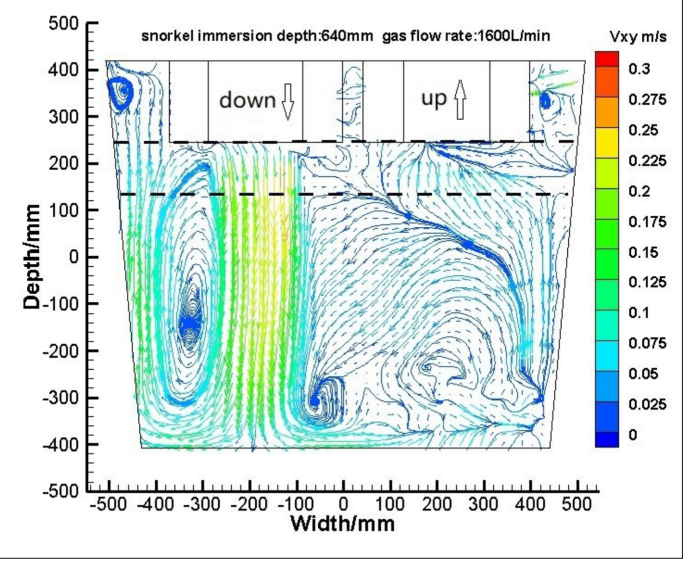

Figure 8. RH ladle flow field with different SIDs: (a) $400 \mathrm{~mm}$; (b) $480 \mathrm{~mm}$; (c) $560 \mathrm{~mm}$; (d) $640 \mathrm{~mm}$; (e) $720 \mathrm{~mm}$. 
Figure 9 is the average of vertical velocity in the transition layer with different SIDs. It shows that the velocity curves on the downward flow left are quite dispersive with different SIDs. The velocity is close to zero when the SIDs is $560 \mathrm{~mm}$, and it increases with the SIDs increasing or decreasing. On the edge of the downward flow, the velocities of different SIDs are relatively coincident. Same as the left part, there is a separation phenomenon in the middle part. The maximum velocity is not located in the center of the downward flow either but on the center-right. The maximum velocity is increasing with the SIDs increasing.

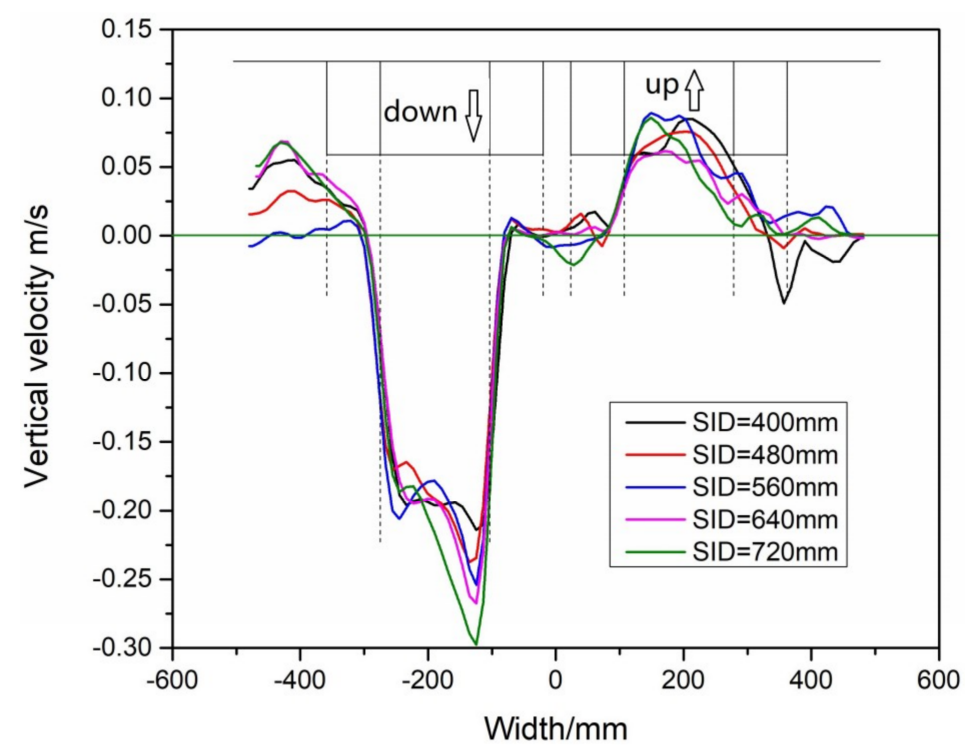

Figure 9. Vertical velocity distribution of flow field in transition layer with different SIDs.

Figure 10 is the average of vertical velocity in the mixing layer with different SIDs. It can be found that the curves are more dispersed than that of the transition layer, while the maximum velocity in the mixing layer is slower than in the transition layer. In addition, the maximum velocity is increasing with the SIDs increasing and the position is closed to the center of the downward flow. On the right of up-leg, near to snorkel wall, the vertical velocity is greater than zero, which means the molten steel under up-leg flows upward along the snorkel wall in the mixing layer.

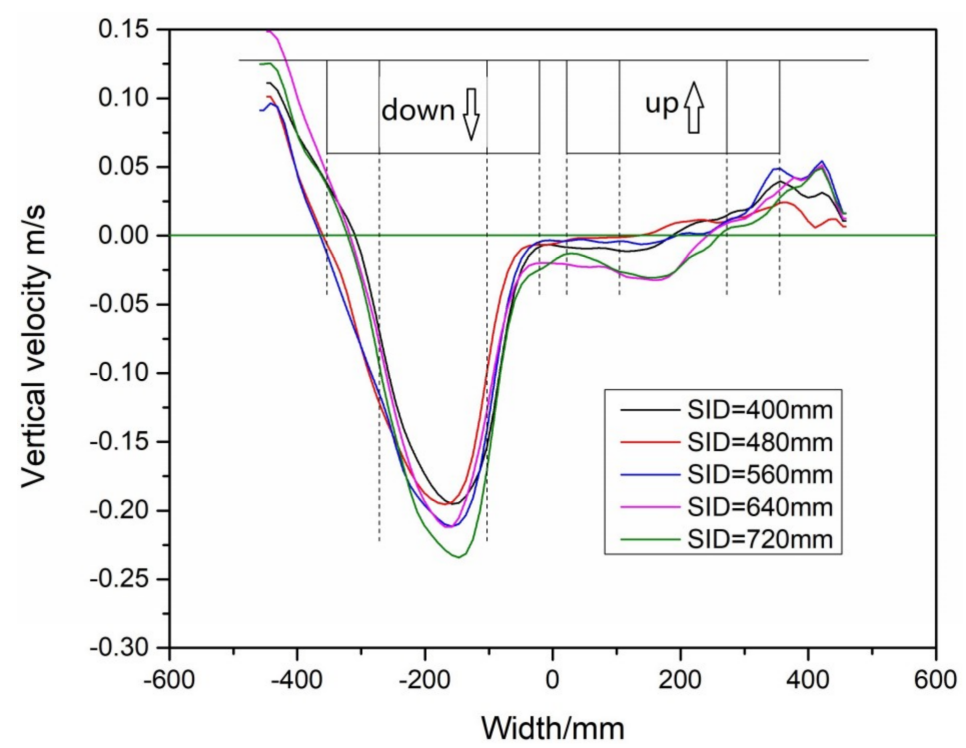

Figure 10. Vertical velocity distribution of flow field in mixing layer with different SIDs. 


\section{Discussion}

An essential function of refining technology is to stir the molten steel well, to make the temperature and composition of molten steel uniform, and to promote the refining reaction to proceed smoothly. A critical index to judge the stirring effect is the mixing time, which is directly related to the homogenization of molten steel composition and temperature. Previous studies [6-10] have shown that mixing time is inversely proportional to the power of stirring power. In fluid mechanics, stirring power, also known as turbulent kinetic energy dissipation rate, can better analyze RH refining process in which turbulent diffusion plays a significant role in mass transfer. Reference [9] shows that the stirring power in $\mathrm{RH}$ device consists of two parts. One part is stirring of molten steel in ladle caused by liquid flow in down-leg, the other part is stirring caused by liquid flow in up-leg in the vacuum chamber. They can be represented by equations respectively as follows:

$$
\begin{gathered}
\varepsilon_{M}=\frac{0.5 Q v^{2}}{W}=\frac{0.375 Q^{3}}{d^{3} W} \\
\varepsilon_{v}=\frac{6.18 G T_{1}}{W}\left[\ln \left(1+\frac{\rho g h}{p}\right)+\left(1-\frac{T_{0}}{T_{1}}\right)\right]
\end{gathered}
$$

where, $\varepsilon_{M}$ and $\varepsilon_{v}$ are the stirring power in $\mathrm{RH}$ ladle and vacuum chamber respectively; $\mathrm{W} / \mathrm{t} ; Q$ is the circulation flow, L/min; $v$ is the flow velocity of down-leg, $\mathrm{m} / \mathrm{s} ; W$ is the mass of circulating fluid, $\mathrm{t} ; d$ is the inner diameter of the down-leg, $\mathrm{m} ; \mathrm{G}$ is the gas blowing flow rate, $\mathrm{L} / \mathrm{min} ; T_{0}$ and $T_{1}$ are molten steel temperature and room temperature, $\mathrm{K} ; \rho$ is the density of liquid steel, $\mathrm{kg} / \mathrm{m}^{3} ; g$ is the acceleration of gravity, $\mathrm{m} / \mathrm{s}^{2} ; h$ is the gas blowing depth, $\mathrm{m} ; p$ is the vacuum chamber pressure, Pa. Therefore, in this work, the main factors affecting $\mathrm{RH}$ ladle stirring power are circulation flow $Q$, and the main factors affecting vacuum chamber stirring power are gas blowing volume $G$ and gas blowing depth $h$.

When the gas blowing rate is increased from $1200 \mathrm{~L} / \mathrm{min}$ to $2400 \mathrm{~L} / \mathrm{min}$, on the one hand, the driving force of gas on the molten steel in the up-leg enhances, and the maximum velocity in $\mathrm{RH}$ ladle increases from $0.248 \mathrm{~m} / \mathrm{s}$ to $0.257 \mathrm{~m} / \mathrm{s}$, indicating that the circulation flow in the whole RH ladle increases. As a result, the stirring power in $\mathrm{RH}$ ladle increases. On the other hand, when the blowing rate $G$ increases, and the blowing depth $h$ is unchanged, the stirring power in the vacuum chamber increases directly. Therefore, $\varepsilon_{M}$ and $\varepsilon_{M}$ both increase with the increase of blowing rate, leading to a decrease of mixing time in Figure 2.

When the SID increases from $400 \mathrm{~mm}$ to $720 \mathrm{~mm}$, on the one hand, the gas blowing depth $h$ increase, leading to the utilization rate of the driving force, generated by the gas, increases in the process of driving the liquid steel circulation. Therefore, the flow velocity of both the transition layer and the mixing layer increases, which means that the circulation flow $Q$ increases, the mixing power increases, and the mixing time decreases at the beginning. On the other hand, as the SID continues to increase, the mass of liquid steel in the vacuum chamber is too much. The gas flow rate is constant, the driving force generated by the gas begins to decrease in the utilization rate of the driving force, result in a decrease of $\varepsilon_{v}$. Meanwhile, as showing in Figure 8, the inactive layer of the flow field expands with the increases of SID, leading to a reduction in mixing effect here. Therefore, when the SID increases to $480 \mathrm{~mm}$, the mixing time is the minimum. After that, the mixing time increases with the increase of SID. These phenomena indicate that in addition to the stirring power, the flow field structure also has a significant impact on the mixing process in the RH ladle.

\section{Conclusions}

(1) At different SIDs, the mixing time decreases with the increase of gas flow rate. Furthermore, the decrease in mixing time becomes smaller and smaller. Under different gas flow rates, the mixing time decreases first and then increases with the increase of SID.

(2) During RH refining process, the flow of molten steel in the ladle is mainly the circulation flow from the down-leg to the up-leg and the return flow around the downward flow. The inactive 
region is mainly within the range of snorkel immersion depth. According to the characteristics of the flow field in RH ladle, the flow field can be divided into the mixing layer, the transition layer, and the inactive layer.

(3) The stirring power and flow field structure have a great impact on the mixing process in the $\mathrm{RH}$ ladle. With the increase of gas blowing rate, the circulation flow in the whole $\mathrm{RH}$ ladle increases. The stirring power in RH ladle and vacuum chamber both increases, leading to the decrease of mixing time. With SID increases from $400 \mathrm{~mm}$ to $480 \mathrm{~mm}$, the gas blowing depth increase. So, the circulation flow increases, the mixing power increases, and the mixing time decrease at the beginning. However, as the SID continues to increase, the utilization rate of the gas driving force begins to decrease because of too-much molten steel. Meanwhile, the inactive layer of the flow field expands with the increases of SID. Therefore, the mixing time increases with the increase of SID.

Author Contributions: Investigation, Y.L.; Project administration, H.C.; Writing - original draft, K.Z. and H.C.; Writing - review \& editing, K.Z., H.C. and R.W.

Funding: This research was funded by the National Natural Science Foundation of China (No. U1860106).

Conflicts of Interest: The authors declare no competing interests.

\section{References}

1. Ajmani, S.K.; Dash, S.K.; Chandra, S.; Bhanu, C. Mixing evaluation in the RH process using mathematical modelling. ISIJ Int. 2004, 44, 82-89.

2. Yamaguchi, K.; Kishimoto, Y.; Sakuraya, T.; Fujii, T.; Aratani, M.; Nishikawa, H. Effect of refining conditions for ultra low carbon steel on decarburization reaction in RH degasser. ISIJ Int. 1992, 32, 126-135.

3. Geng, D.Q.; Lei, H.; He, J.C. Effect of traveling magnetic field on flow, mixing, decarburization and inclusion removal during $\mathrm{RH}$ refining process. ISIJ Int. 2012, 52, 1036-1044. [CrossRef]

4. Kato, Y.; Nakato, H.; Fujii, T.; Ohmiya, S.; Takatori, S. Fluid flow in ladle and its effects on decarburization rate in RH degasser. ISIJ Int. 1993, 33, 1088-1094.

5. Ai, X.G.; Bao, Y.P.; Jiang, W.; Liu, J.H.; Li, P.H.; Li, T.Q. Periodic flow characteristics during RH vacuum circulation refining. Int. J. Miner. Metall. Mater. 2010, 17, 17-21. [CrossRef]

6. Mukherjee, D.; Shukla, A.K.; Senk, D.G. Cold Model-Based Investigations to Study the Effects of Operational and Nonoperational Parameters on the Ruhrstahl-Heraeus Degassing Process. MMTB 2017, 48, 763-771. [CrossRef]

7. Lin, L.; Bao, Y.P.; Yue, F.; Zhang, L.Q.; Qu, H.L. Physical model of fluid characteristics in RH-TOP vacuum refining process. Int. J. Miner. Metall. Mater. 2012, 19, 483-489. [CrossRef]

8. Nakanishi, K.; Szekely, J.; Chang, C. Experiments and theoretical investigation of mixing phenomena in the RH-vacuum process. Ironmak. Steelmak. 1975, 2, 115-124.

9. Zhang, L.F.; LI, F. Investigation on the fluid flow and Mixing phenomena in a Ruhrstahl-Hereaus (RH) steel degasser using physical modeling. JOM 2014, 66, 1227-1240. [CrossRef]

10. Niu, D.L.; Ma, D.G.; Yang, J.; Xu, M.R.; Wang, Z. Characteristics of the dead zones in RH desgasser with simulation methods. Mater. Sci. Forum 2015, 817, 755-763. [CrossRef]

11. Chen, G.J.; He, S.P. Mixing behavior in the RH degasser with bottom gas injection. Vacuum 2016, 130, 48-55. [CrossRef]

12. Kishan, P.A.; Dash, S.K. Mixing time in RH ladle with upleg size and immersion depth: A new correlation. ISIJ Int. 2007, 47, 1549-1551. [CrossRef]

13. Zhu, B.H.; Chattopadhyay, K.; Hu, X.P.; Zhang, B.; Liu, Q.C. Optimization of sampling location in the ladle during RH vacuum refining process. Vacuum 2018, 152, 30-39. [CrossRef]

14. Li, F.; Zhang, L.F.; Liu, Y.; Li, Y.L. Study of Mixing Phenomena during RH Refining Using Water Modeling. TMS (The Minerals, Metals $\mathcal{E}$ Materials Society) 2014, 57, 459-466.

15. Ling, H.T.; Guo, C.B.; Conejo, A.N.; Li, F.; Zhang, L.F. Effect of snorkel shape and number of nozzles on mixing phenomena in the RH process by physical modeling. Metall. Res. Technol. 2017, 114, 111-123. [CrossRef]

16. Pieprzyca, J.; Merder, T.; Saternus, M.; Michalek, K. Physical modelling of the steel flow in RH apparatus. Arch. Metall. Mater. 2015, 60, 1861-1864. [CrossRef] 
17. He, S.; Chen, G.; Guo, C. Investigation of mixing and slag layer behaviours in the RH degasser with bottom gas injection by using the VOF-DPM coupled model. Ironmak. Steelmak. 2017, 44, 1-6. [CrossRef]

18. Geng, D.Q.; Lei, H.; He, J.C. Numerical simulation of the multiphase flow in the Rheinsahl-Heraeus (RH) system. МMTB 2009, 41, 234-247. [CrossRef]

19. Tsujino, R.; Nakashima, J.; Hirai, M.; Sawada, I. Numerical analysis of molten steel flow in ladle of RH process. ISIJ Int. 1989, 29, 589-595.

20. Liu, C.; Duan, H.J.; Zhang, L.F. Modeling of the melting of aluminum particles during the RH refining process. Metals 2019, 9, 442. [CrossRef]

(C) 2019 by the authors. Licensee MDPI, Basel, Switzerland. This article is an open access article distributed under the terms and conditions of the Creative Commons Attribution (CC BY) license (http://creativecommons.org/licenses/by/4.0/). 